\title{
Level of pain and physical function in patient with chronic knee pain visiting Dhulikhel hospital: A cross sectional study
}

Binaya Kandel ( $\sim$ kandelbinay@gmail.com )

Kathmandu University School of Medical Sciences https://orcid.org/0000-0003-2059-3029

Surakshya Badal

Kathmandu University School of Medical Sciences

\section{Research article}

Keywords: Chronic Knee pain, knee osteoarthritis, pain level, physical function

Posted Date: September 21st, 2020

DOI: https://doi.org/10.21203/rs.3.rs-74073/v1

License: (c) (1) This work is licensed under a Creative Commons Attribution 4.0 International License.

Read Full License 


\section{Abstract \\ Background}

Knee pain is one of the common causes of chronic pain mainly in the older adults.Chronic knee pain (CKP) is commonly due to arthritic changes (osteoarthritis). Chronic knee pain is a common and major health problem in ageing population. Knee pain is associated with high levels of disability. So early detection and treatment of pain related functional limitation is likely to have major influence on healthy ageing. The general objective of this study was to quantify the level of pain and physical function in patient with CKP.

\section{Methods}

Preliminary screening of population with chronic knee pain was taken and cross sectional descriptive study was done. Questionnaire with inclusion criteria was fulfilled with administration of Nepali version of Numerical Pain Rating Scale and Nepali version of Patient Specific Functional Scale on interview as well as self-report basis and the data was managed by SPSS version 23.

\section{Results}

$75.6 \%$ of female with chronic knee pain was found with the average pain level found to be 5 in N-NPRS scale.Among them $80.8 \%$ of chronic knee pain was due to knee osteoarthritis. Sitting function was found to be affected in $82.1 \%$ of population with mean Nepali version of Patient specific functional Scale score of 2 . Similarly $80.8 \%$ reported going downstairs to be difficult due to knee pain with N-PSFS score of 2.

\section{Conclusion}

Pain and functional disability are the principle findings in patient with chronic knee pain for which they seek medical treatment .So the treatments should target on functional task with effective strategy. addressing disability. Focus on function is important for the development of optimal rehabilitation programs in patients with chronic knee pain.

\section{Background}

Pain is defined as unpleasant sensory or emotional disturbance that occurs due to actual or potential tissue damage [1].So the pain is considered to be chronic if the duration of pain is more than 3 month and pain prolongs past normal healing time and hence lack the acute warning function of the physiological nociception [2, 3]. There are seven classification of chronic pain where chronic knee pain falls mainly under chronic musculoskeletal pain [3].Knee pain is one of the common causes of chronic pain mainly in the older adults $[3,4]$. 
In a study done in the community dwelling adults of Iran, the prevalence of chronic knee pain was found to be $29.97 \%$ [5].Chronic knee pain is commonly due to arthritic change and knee osteoarthritis is one of the leading cause of chronic knee pain[6]. The patellofemoral pain syndrome is one of the leading causes of pain in adults and adolescents [7].Since knee is one of the largest weight bearing joint in our body, it is always prone to overload and overuse causing pain and limiting the lower limb function [8]. Usually the mechanical axis passes through or just medial to the centre of the knee joint in the coronal plane [9]. Deviation of the mechanical axis away from this leads to increased contact stresses at the joint surface. Mainly during maximum knee flexion of 20 degree, the patellofemoral compressive force is approximately 25 to $50 \%$ of body weight[9]. The consequence of the altered biomechanics of the knee leads to chronic symptoms[10].People with knee pain have 5 fold raise in risk of worst lower extremity function compared to people without knee pain [12]. Chronic knee pain is associated with functional impairment and this will cause social isolation[12, 13]. In a study prevalence of chronic knee pain was found to be $12.1 \%$ [14]. Most of the participants in the study were not able to go uphill and downhill. Chronic knee pain is a major health problem and is also very common in ageing population [14].Kneeling, squatting on the toilet, carrying heavy weights, getting on and off the toilet, were the activities that had the greatest proportion of participants reporting knee pain[14].Knee pain is associated with high levels of disability [9]. So early treatment of pain related functional limitation is likely to have major influence on healthy ageing for adult with chronic knee pain.Functional exercises are regarded in rehabilitation to restore good knee function $[12,13]$.

Pain is the main complain of people living with osteoarthritis and they are distressed mainly because of its impact on their physical function $[15,16]$. Identification of the key impairments related to pain and function may assist in delineating physical therapy treatment approaches for patients with PFPS. If it can be shown that particular impairments are associated with function and pain, targeting such impairments may improve the effectiveness of physical therapy for patients with PFPS [17].The exercise that will improve the physical factors will be based on functional exercise[18]. A home based program based on functional exercises and the management of kinesiophobia was useful in changing the course of disability, fear-avoidance beliefs, pain, and the quality of life in patients with TKA [19].

\section{Methods}

\section{Study type and design}

A cross sectional study was designed as the study aimed to determine the level of pain and function with the demographic characteristics of people with chronic knee pain

\section{Place and duration of study}

Dhulikhel Hospital: Physiotherapy outpatient department and orthopedic outpatient department.It is an excellent site for data collection as it receives patients with knee pain from both rural and urban communities with different ethnicity and background making the sample more representative. The data was collected within 2 weeks of times and the study was done within 6 month of time. 


\section{Sample size and sampling method}

A total of 78 participants was recruited after calculating sample size for non probability convenience sampling method for this study

\section{Methods of data collection}

Individuals with chronic knee pain and who show willingness to participate in the study were screened for the eligibility criteria. After screening, participants who were eligible were provided with a subjective information sheet. The participants were provided with demographic form with N-NPRS and N-PSFS questionnaire to fill up which took 3.5 to 5 minutes to complete. The data was collected, recorded and analyzed using Statistical Package for the Social Sciences (SPSS) version 23.

\section{Ethical approval and consent}

This research was conducted after the approval from Institutional Review Committee, Kathmandu University School of Medical Sciences considering the guidelines to conduct research given by Declaration of Helsinki. Written informed consent was obtained from all participants prior to data collection. Verbal consent was obtained if the participants could not sign, and a witness signed on their behalf.

\section{Inclusion and exclusion criteria}

\section{Inclusion criteria:}

- Male and female participants of 18 years and above

- Participants who understands Nepali

- Participants who have knee pain for minimum 3 months

\section{Exclusion criteria:}

- Malignant conditions like Carcinoma of knee and other body parts.

- Recent knee surgery/ trauma / fractures (less than 3 months)

\section{Statistical analysis and software used}

Statistical analysis was done by using SPSS version 23 and78participants was be recruited from the formula of Sample size calculation: 


\section{$\mathrm{N}=\frac{\mathrm{z}^{2} \mathrm{p}(1-\mathrm{p})}{\mathrm{d}^{2}}$}

Where, $\quad z=$ desired level of significance (1.96)

$\mathrm{p}=$ prevalence of chronic knee pain $(12.1 \%)$

$\mathrm{d}=$ precision value $(0.07)$

\section{Outcome Measures}

We used Nepali version of numerical pain rating scale and Nepali version of patient specific functional scale. NPRS is routinely used outcome measure for accessing the pain intensity in daily clinical practice. Out of many versions, the 11 point NPRS is most commonly preferred. It has acceptable psychometric properties. One of the main advantages of NPRS is that it can be used by people with low level of literacy as well and is routinely used in many countries and languages. NPRS-NP showed excellent test-retest reliability and a MDC of 1.13 points. NPRS-NP demonstrated a good construct validity The anchor on the left side corresponds to "no pain" that is zero and the anchor at the right side corresponds to the "worst possible pain" or "maximum pain". It was administered by patient self-report and by face to face interview[25,26].Patient specific functional scale is a patient reported outcome measure in which patient themselves identifies the activity that are most important to them and rate them in a scale of 0 to 10 where higher score shows the better physical function. The proposed advantages of the PSFS include its wide applicability and ease of use clinically. PSFS-NP showed good reliability with Cronbach's alpha = 0.75 ; ICC $=0.89$. Self-reported difficulty in function using scale from the questionnaire was done in our study [27].

\section{Results}

Data were collected from the 78 participants. Descriptive statistics of the demographic characteristics, knee pain results and PSFS-NPRS findings are illustrated in table I, II and III respectively. Similarly, distribution by PSFS findings is depicted in Fig. 1.

The mean age of the patient was $52.59 \pm 14.98$ years.75.6\% of the participants with chronic knee pain were female. Among 78 participants $80.8 \%$ of them were illiterate and $46.2 \%$ of them were farmers. Newar community patients were more i.e. $37.2 \%$. Chronic knee pain was found to be more in illiterate female patients who were mostly farmer.Knee OA was the main cause of Chronic Knee pain followed by patella femoral pain syndrome. Bilateral knee pain was found to be prevalent in $59 \%$ of the patient with mean duration of 20 month.

Table III shows about the functional level of the population where sitting function was found to be affected in $82.1 \%$ of population with mean PSFS score of 2. Similarly carrying load was found to be the most difficult task with PSFS score of 1. Mean pain level of patient with chronic knee pain in numerical pain rating scale was 5 with maximum score of 7 and minimum score of 2 . 


\section{Discussion}

The study shows sitting function was mostly affected in $82.1 \%$ of population with mean PSFS score of 2 . Similarly carrying load was the most difficult task with mean PSFS score of $1.80 .8 \%$ of them reported going downstairs to be difficult due to knee pain with PSFS score of 2. Going upstairs was found to be difficult for $74.4 \%$ with PSFS score of 3 . Mean pain level of patient with chronic knee pain in Nepali version of Numerical Pain Rating scale was 5 with maximum NPRS score7 and minimum score of 2.0. The main cause of chronic knee pain in following study shows knee osteoarthritis which is consistent with the similar study that has been done in Iran[5].

To the best of our knowledge no prior study has been done about pain level in chronic knee pain using the NPRS scale; thus a direct comparison of present findings with the other studies couldn't be made. One study reported the baseline score of pain of people with Knee osteoarthritis to be 5.9 in Numerical rating scale which is expressed in a scale of 0 to 10 [10]. Combination of tibio-femoral and patello-femoral pain was associated with greater self- reported pain. The difference in pain between individual can be due to risk factors like age and gender[12]. There are studies suggesting that the psychological factors and the structural damage to the surrounding structures were the leading causes of pain [13]. Although this study didn't considered the level of pain during rest or movement, the rest pain in previous study shows 2 in VAS and 7 with the movement [29].

It may be argued that the specific site of cartilage destruction within a joint might explain the presence of pain at rest and/or movement [29]. CKP was found to be more in female patients than in the male patients in the present study which is consistent with a study that has been done in Japan. This type of finding warrants the sex specific preventive measures and management of chronic knee pain [30]. Studies have indicated that individuals in the older age group perform less functional activities than younger counterparts. [31]This will lead to muscle dysfunction and finally osteoarthritis of knee [31]. In old age group, there is decline in the number of proprioceptors due to muscle atrophy and weakness. Increase knee ROM requirements during weight bearing activities such as going up and down, sit to stand can significantly elevate the tibiofemoral and pattelofemoral joint compressive forces leading to greater pain and thus rendering task performance difficult [32]. Reduced muscle activation leads to reduction in joint proprioception as a result of decreased functional activity. Hence there is increase in nociceptors. [31, 32].Diminished quadriceps strength is an important determinant of functional loss [34]. .Reduced muscle activation leads to reduction in joint proprioception as a result of decreased functional activity. Hence there is increase in nociceptors. [31, 32].. It was theorized that knee joint proprioception is essential for accurate modulation and activation of muscles [34]. When proprioceptive acuity decreases, functional ability can only be maintained if there is sufficient muscle strength to compensate for the decrease in accuracy of modulation and activation of muscles [34]. Thus, it was predicted that functional ability will be more strongly affected in the presence of both proprioceptive inaccuracy and muscle weakness [34].

It is necessary to focus on the functional consequence which is important because knowledge of functional consequences is essential for development of optimal rehabilitation programs inpatient with 
CKP.[32]

Limitation of the study

First the study is a cross sectional study design so no casual conclusions can be drawn from the study results. Secondly, the association of pain and function was not analyzed. Psychological variables and health related beliefs are important determinants of functioning which was not analyzed in this study which is another potential limitation of the study.

\section{Conclusion}

Pain and functional limitation was main finding among the population with chronic knee pain. Regarding function, sitting function was mainly hampered. Along with this sit to stand, walking in upstairs and downstairs were also significantly affected. Knee osteoarthritis was the main cause of CKP. Proper functional rehabilitation protocol is necessary for such population .Olderage group was found with more pain as well as functional problem. So the functional rehabilitation should have focus on the older age group.To conclude knowledge of functional consequences is essential for development of optimal rehabilitation programs inpatient with CKP. Identification of the key impairments related to pain and function may assist in delineating physical therapy treatment approaches for patients with CKP.

\section{Recommendation}

Factors like medication, depression might have influenced the self-reported functional limitation of participants. So further study should be done regarding these factors.

\section{Abbreviations}

CKP

Chronic Knee Pain

$\mathrm{N}$-NPRS

Nepali version of Numerical Pain Rating Scale N-PSFS

Nepali version of Patient Specific Functional Scale

IRC

Institutional Review Committee

KUSMS

Kathmandu University School of Medical Sciences

SPSS

Statistical Package for the Social Sciences

PFPS

Patellofemoral Pain Syndrome 
TKA

Total Knee Arthroplasty

MDC

Minimal Detectable Change

ICC

Inter-class Correlation Coefficient

\section{Declarations}

\section{Ethics approval and consent to participate}

Study was approved by the Institutional Review Committee of Kathmandu University School of Medical Sciences, Dhulikhel, Nepal (ethical approval number 141/19.

Informed consent to participate in the study was obtained from all participants.

\section{Consent for publication}

Not Applicable

\section{Availability of data and materials}

The data sets used and/or analyzed during the current study are available from the corresponding author on reasonable request.

\section{Competing interests}

\section{The authors declare that they have no competing interests,}

\section{Funding}

No funding received.

\section{Authors' contribution}

BK led the concept and design of the study, SB did the literature search data acquisition and performed the statistical analyses. BK drafted the manuscript with important intellectual content. Also tabulated the results and illustrated the figures to conclude the study. BK was involved in the review of the draft manuscript, read, and approved the final version prior to submission.BK being the corresponding author is responsible for submission and follow up.

\section{Acknowledgement}

The authors would like to thank Sarita Koju for helping in data collection. This work would have been in complete without the help of Rakshya Neupane, Saurab Sharma and Roshan Mahato for helping in data analysis and to all the participants for their voluntary participation. 


\section{References}

1. Loeser JD, Treede RD. The Kyoto protocol of IASP basic pain Terminology. Journal of Pain. 2008 July 31; 137(3):473-7.

2. Denovo DJ, Hoeskema LJ, Hobbs RD. Caring for patients with chronic pain. Journal of American osteopathic association. 2013;113(8):620-7.

3. Trede RD, Rief W, Barke A, Aziz Q,Bennet MI, Benoliel R, Cohen M, Evers S,Finnerup NB,First MB,Giamberadino MA.A classification of chronic pain for ICD-11.Pain Journal.2015 june;156(6):1003.

4. Jinks C, Jordan K, Croft. and P. Osteoarthritis as a public health problem: the impact of developing knee pain on physical function in adults living in the community: (KNEST 3). Rheumatology. 2007;46(5):877-81.

5. Noormohammadpour P, Mansournia MA, Koohpayehzadeh J, Asgari F, Rostami M, Rafei A, Kordi R. Prevalence of chronic neck pain, low back pain, and knee pain and their related factors in community-dwelling adults in Iran. The Clinical journal of pain. 2017 Feb 1;33(2):181-7.

6. Hosny S, McClatchie W, Sofat N, Hing CB. Knee Pain in Adults \& Adolescents, Diagnosis and Treatment. Pain in Perspective.2012 Oct 24;DOI 10.5772/51077.

7. Rathleff MS, Vicenzino B. Patellofemoral Joint Pain, fact sheet. International association for study of pain.(2016).

8. MuraseK TY, Ito H, Kobayashi MTakahashi Y, Setoh K. Knee pain and low back pain Additively Disturb sleep in the general population : A Cross sectional analysis of the Nagahma study 2015; 10(10).

9. Magee DJ.Orthopedic physical assessment. Elsevier health Sciences; 2013 Dec 4 ; Chap. 11:427428.

10. Lohmander LS, Östenberg A, Englund M, Roos H. High prevalence of knee osteoarthritis, pain, and functional limitations in female soccer players twelve years after anterior cruciate ligament injury. Arthritis Rheumatism: Official Journal of the American College of Rheumatology. 2004 Oct;50(10):3145-52.

11. Kim W, Jin YS, Lee CS, Bin SI, Lee SY, Choi KH. Influence of knee pain and low back pain on the quality of life in adults older than 50 years of age. Journal of PMR. 2014;7(9):955-61.

12. Farrokhi Shawn CF, Yi PR, Sara, Fitz KG, Gerald. Jong - Hyeon Jeong and C. Kent Kwoh. The influence of knee pain location on symptoms, functional status and knee-related quality of life in older adults with chronic knee pain. Clinical journal of pain. 2017;32(6):463-70.

13. GM Dijk van, Dekker J, Veenhof C, Van den Ende $\mathrm{CH}$. Carpa study group. Course of functional status and pain in osteoarthritis of the hip or knee: a systematic review of the literature. Journal of arthritis care and research. 2006;55(5).

14. Kshetri Dan. Knee pain and knee pain related disability in adults of the Western Development Region of Nepal.PHD thesis.Preston :University of central Lanchasire;2017. 
15. Werner Suzanne. Anterior knee pain: An update of physical therapy. Journal of knee surgery and sports traumatology,arthroscopy.2014;22(10):2286.

16. Hawker G. Assessing joint pain and function in the clinic.International association of pain.2016.

17. Piva SR, Fitzgerald GK, Irrgang JJ, Fritz JM, Wisniewski S, McGinty GT, Childs JD, Domenech MA, Jones S, Delitto A. Associates of physical function and pain in patients with patellofemoral pain syndrome. Archives of physical medicine and rehabilitation. 2009 Feb 1;90(2):285 - 95.

18. Effect study of. an intervention on pain,function, health and behavior for older adults living with chronic pain. 2016.

19. Monticone M, Ferrante S, Rocca B, Salvaderi S, Fiorentini R, Restelli M, Foti C. Home-based functional exercises aimed at managing kinesiophobia contribute to improving disability and quality of life of patients undergoing total knee arthroplasty: a randomized controlled trial. Archives of physical medicine and rehabilitation. 2013 Feb 1;94(2):231-9.

20. Cottrell E, Roddy E, Foster NE. The attitudes, beliefs and behaviours of GPs regarding exercise for chronic knee pain: a systematic review. BMC Fam Pract. 2010 Dec;11(1):4.

21. Dunlop DD, Lyons JS, Manheim LM, Song J, Chang RW. Arthritis and heart disease as risk factors for major depression: the role of functional limitation. Med care. 2004;42:502-11.

22. Tichonova A, Rimdeikienè I, Petruševičienè D, Lendraitienè $E$. The relationship between pain catastrophizing, kinesiophobia and subjective knee function during rehabilitation following anterior cruciate ligament reconstruction and meniscectomy: A pilot study. Medicina. 2016 Aug;52(4):22937.

23. Agaliotis M, Mackey MG, Jan S, Fransen M. Burden of reduced work productivity among people with chronic knee pain: a systematic review. Occup Environ Med. 2014 Sep;1(9):651-9. 71(.

24. Cross M, Smith E, Hoy D, Nolte S, Ackerman I, Fransen M, Bridgett L, Williams S, Guillemin F, Hill CL, Laslett LL. The global burden of hip and knee osteoarthritis: estimates from the global burden of disease 2010 study. Annals of the rheumatic diseases. 2014 Jul 1;73(7):1323-30.

25. Sharma Saurab P, Joshna R, Darren, Abbott Haxby J. Translation, cross-cultural adaptation and psychometric properties of the Nepali versions of numerical pain rating scale and global rating of change. Journal of BMC. 2017;081:2-8.

26. Castarlenas, ElenaJensen. Mark Pvon Baeyer, Carl LMiró and Jordi Psychometric Properties of the Numerical Rating Scale to Assess Self-Reported Pain Intensity in Children and Adolescents A Systematic Review. Clinical journal of pain. 2017;23(4):376-83.

27. Sharma Saurab,Palanchoke Joshna and Abbott. haxby J. Cross-cultural adaptation and validation of the Nepali translation of the Patient-Specific Functional Scale. Journal of Orthopedic Sports Physical Therapy.2018;48(8):659-64.

28. Alghadir AH, Anwer S, lqbal A, Iqbal ZA. Test-retest reliability, validity, and minimum detectable change of visual analog, numerical rating, and verbal rating scales for measurement of osteoarthritic knee pain. Journal of pain research. 2018;11:851. 
29. Lundblad H, Kreicbergs A, Jansson K. Prediction of persistent pain after total knee replacement for osteoarthritis. J Bone Joint Surg Br Vol. 2008 Feb;90(2):166-71.

30. Takahashi A, Kitamura K, Watanabe Y, Kobayashi R, Saito T, Takachi R, Kabasawa K, Oshiki R, Tsugane S, Iki M, Sasaki A. Epidemiological profiles of chronic low back and knee pain in middleaged and elderly Japanese from the Murakami cohort. Journal of pain research. 2018;11:3161.

31. Hortobágyi T, Garry J, Holbert D, Devita P. Aberrations in the control of quadriceps muscle force in patients with knee osteoarthritis. Arthritis Care Res. 2004 Aug;15(4):562-9. 51(.

32. Dekker J, van Dijk GM, Veenhof C. Risk factors for functional decline in osteoarthritis of the hip or knee. Current opinion in rheumatology. 2009 Sep 1;21(5):520-4.

33. Pisters MF, Veenhof C, Van Dijk GM, Heymans MW, Twisk JW, Dekker J. The course of limitations in activities over 5 years in patients with knee and hip osteoarthritis with moderate functional limitations: risk factors for future functional decline. Osteoarthritis and cartilage. $2012 \mathrm{Jun}$ 1;20(6):503 - 10 .

34. Van der Esch M, Steultjens M, Harlaar J, Knol D, Lems W, Dekker J. Joint proprioception, muscle strength, and functional ability in patients with osteoarthritis of the knee. Arthritis Care Research: Official Journal of the American College of Rheumatology. 2007 Jun;15(5):787-93. 57(.

\section{Tables}

Table l: Demographic characteristics of sample $(\mathrm{N}=78)$ 


\begin{tabular}{|c|c|c|}
\hline Characteristics & $\mathbf{N}$ & Percentage \\
\hline \multicolumn{3}{|l|}{ Sex } \\
\hline Male & 19 & 24.4 \\
\hline Female & 59 & 75.6 \\
\hline \multicolumn{3}{|l|}{ Educational status } \\
\hline Illiterate & 63 & 80.8 \\
\hline Primary & 7 & 9.0 \\
\hline Secondary & 6 & 7.7 \\
\hline Bachelor and above & 2 & 2.6 \\
\hline \multicolumn{3}{|l|}{ Occupation } \\
\hline Farmer & 36 & 46.2 \\
\hline Business & 7 & 9 \\
\hline Student & 4 & 5.1 \\
\hline Housewife & 26 & 33.3 \\
\hline Unemployed & 2 & 2.6 \\
\hline Others & 3 & 3.8 \\
\hline \multicolumn{3}{|l|}{ Ethnicity } \\
\hline Brahmin & 23 & 29.5 \\
\hline Newar & 5 & 37.2 \\
\hline Chhetri & 29 & 6.4 \\
\hline Tamang & 12 & 15.4 \\
\hline Others & 9 & 11.5 \\
\hline Age & Mean ( standard deviation) & Range \\
\hline Years & $52.59(14.98)$ & $18-82$ \\
\hline
\end{tabular}

Table Il: Features of Knee pain $(\mathrm{N}=78)$ 


\begin{tabular}{|lll|}
\hline & N & Percentage \\
\hline Diagnosis of knee pain & & \\
\hline Knee OA & 63 & 80.8 \\
\hline Patello femoral pain syndrome & 10 & 12.8 \\
\hline Chronic post- surgical pain & 5 & 6.4 \\
\hline Side of knee pain & & \\
\hline Right & 25 & 32.1 \\
\hline Left & 7 & 9.0 \\
\hline Bilateral & 46 & 59.0 \\
\hline Duration of knee pain & Mean (standard deviation) & Range \\
\hline Months & $20.09(22.43)$ & $4-96$ \\
\hline
\end{tabular}

Table III: PSFS and NPRS Findings $(\mathrm{N}=78)$

\begin{tabular}{|llll|}
\hline & $\mathbf{N}$ & Percentage & $\begin{array}{l}\text { PSFS } \\
\text { score(average) }\end{array}$ \\
\hline Activities & & & \\
\hline Sitting & 64 & 82.1 & 2 \\
\hline Going downstairs & 63 & 80.8 & 3 \\
\hline Going upstairs & 58 & 74.4 & 2 \\
\hline Sit to stand & 51 & 65.4 & 3 \\
\hline Walking & 48 & 61.5 & 2 \\
\hline Toileting & 47 & 60.3 & 3 \\
\hline Prolong standing & 32 & 41.0 & 1 \\
\hline Carry load & 10 & 12.8 & 4 \\
\hline Bending & 1 & 1.3 & Total \\
\hline NPRS Findings & Male & Female & $5.1( \pm 1.04)[2-7]$ \\
\hline $\begin{array}{l}\text { Mean (Standard deviation) } \\
\text { [range) }\end{array}$ & $5.15( \pm 1.03)[2.3-$ & $5.12( \pm 1.04)[2-$ & \\
\hline
\end{tabular}

Figures 


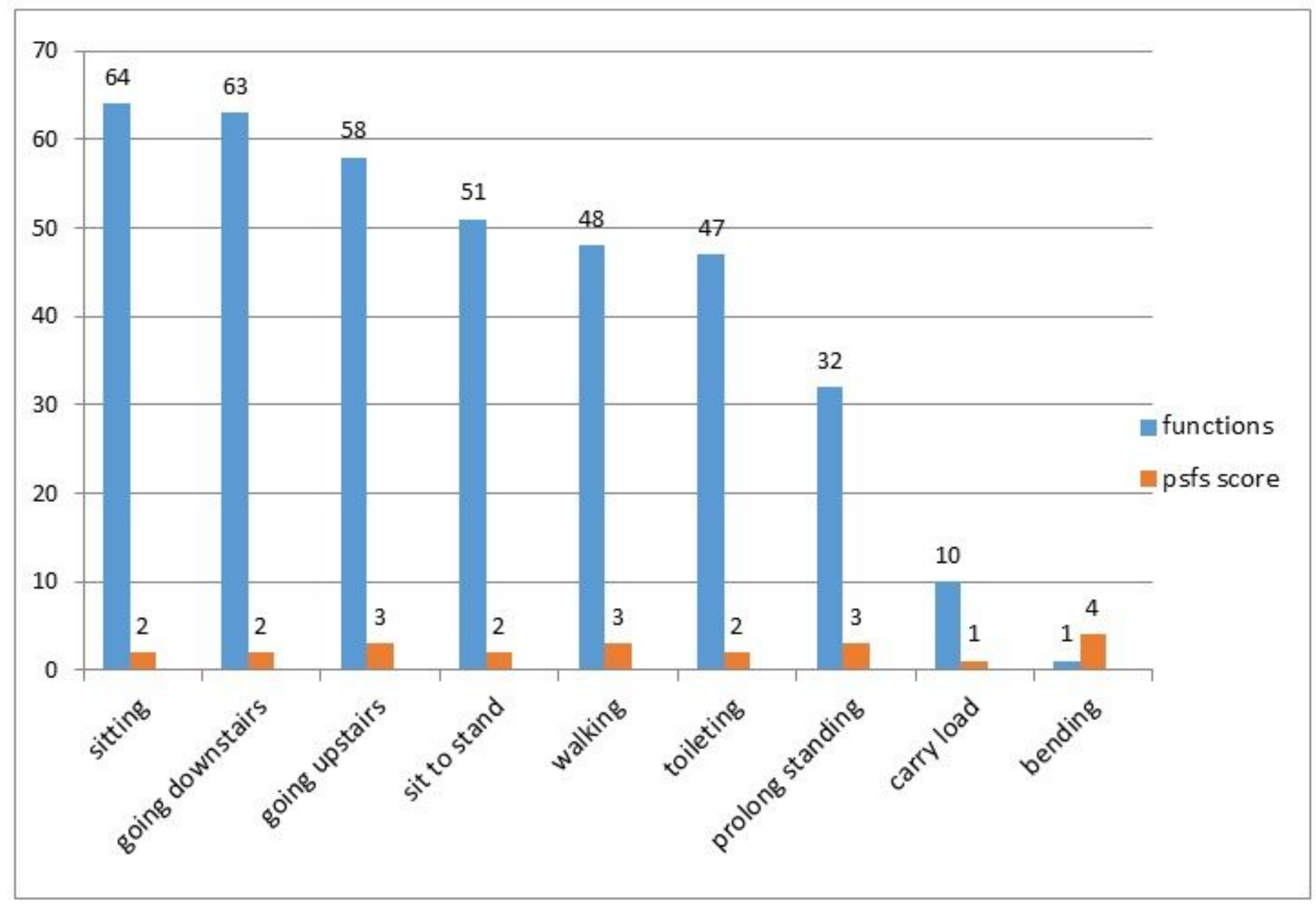

Figure 1

Distribution by PSFS score 